\title{
Synthesis and Characterization of Polyesters derived from Glycerol and Phthalic Acid
}

Danilo Hansen Guimarães a, Michel de Meireles Brioudea, Raigens da Paz Fiúza

\author{
Luis Antônio Sanches de Almeida Prado ${ }^{\text {b }}$, Jaime Soares Boaventura ${ }^{\text {a }}$, Nadia Mamede Joséa* \\ ${ }^{a}$ Programa de Pós-graduação de Engenharia Química, Instituto de Química, \\ Universidade Federal da Bahia, Campus de Ondina, 40170-290 Salvador - BA, Brasil \\ ${ }^{\mathrm{b}}$ Institute of Polymer and Composites, Technische Universität Hamburg, Harburg
}

Received: December 12, 2006; Revised: August 22, 2007

\begin{abstract}
The production of polyester via polycondensation between glycerol and phthalic acid using dibutyltin dilaurate is reported. Three glycerol:phthalic acid molar ratio used for the bulk polymerization were: $2: 2 ; 2: 3$ and $2: 4$. FTIR confirmed the esterification of glycerol by the acid for all the polymers. DSC indicated no crystallinity, although the XRD plots indicate a very incipient crystallinity for the polymers containing higher amounts of phthalic anhydride. Scanning electron microscopy results indicates high homogeneity for all the polymers prepared.
\end{abstract}

Keywords: polyester, glycerol, phthalic acid

\section{Introduction}

The development of renewable energy sources are a key issue in the coming decades due to the insufficiency of petroleum in the near future. Another aspect is related to the pollution, which is generated by the use of fossil fuels, and the consequences to the environment and climate.

In this context, bio-diesel achieves many of the requirements, since its combustion produces no toxic gases like sulphur oxides, nitrogen oxides are produced during its combustion. The combustion of bio-diesel yields $75 \%$ less $\mathrm{CO}_{2}$ than the diesel obtained from petroleum. The glycerol is the by-product from the esterification of vegetal oils, which is also obtained during the preparation of bio-die$\operatorname{sel}^{1}$. This alcohol can be synthesized through fermentation or other chemical processes. Although many uses have been described for the glycerol (cosmetics, pharmaceutical applications, manufacturing of resins, among others), the demand is still increasing mostly in dental care (tooth paste) and food industries.

The development of direct-alcohol fuel cells ${ }^{2}$, which produces electricity through electrochemical oxidation of alcohols (e.g. methanol) into $\mathrm{CO}_{2}$, opened a new market for glycerol. Modern catalysts may oxidize alcohols ${ }^{3,4}$ in the operating condition of fuel cells, and use these alcohols for producing energy in a environmentally friendly way. Another application of glycerol is related to its conversion to hydrogen, for Fuel Cell applications ${ }^{5}$. InnovaTek (USA) has already used its technology to produce hydrogen from glycerol (a by-product of biodiesel production), and the raw soybean oil that is used to manufacture the biodiesel fuel ${ }^{6}$. The use of glycerol as a source for hydrogen has the additional advantage of producing a valuable commodity from a by-product of biodiesel production. This benefit contributes favorably to the economics of biodiesel as a fuel that is competitive with petroleum diesel fuel ${ }^{7}$.

In the present context, we want to give a further input for the development of bio-diesel, by using the glycerol for the production of polyesters derived from glycerol and phthalic acids ${ }^{8,9}$. The esters derived from the phthalic acids have found many applications. For instance, poly(ethylene terephtalate), PET, has excellent mechanical properties and is used for the manufacturing of plastic bottles for car-

*e-mail: nadia@ufba.br bonated beverages (soft drinks, etc... ${ }^{10}$. Poly(butylene therephtalate), PBT, can be used for a wide range of applications, for example, for thin-walled injection-moulded parts in electrical engineering applications, for especially dimensionally stable components of high surface quality in the automotive industry, as a barrier layer in multilayer fuel lines, and in the cable industry ${ }^{11}$. PBT is also is used in plug-in connectors, connector strips, switching systems, housings for automatic cut-outs, capacitor pots, in coil formers, lamp parts, PC fans, power supply components, parts for electric drives, sheathing for waveguides and many other products and not least in vehicle electrical systems (ignition coil housing) ${ }^{12}$. High-molecular extrudable PBT specialty products have come to occupy a leading position as materials for secondary fibre optic jacketing, because they fulfil the requirements perfectly. When dealing with automobile industry, PBT is one of the suitable components for bumpers ${ }^{13}$, and fenders ${ }^{14}$. Furthermore, the development of new elastomers derived from PBT (or PET) and poly(tetramethylene oxide) (also poly(dimethyl siloxane)), which combine the processability of the thermoplastics and the good mechanical properties of the elastomers have been investigated for decades ${ }^{15-19}$. The preparation of polyesters from multi-functional phenols and phthalic acid gave rise to production of gas separation membranes with good selectivity coefficients ${ }^{9}$.

Therefore, the production of polyesters from glycerol and phthalic acid should produce new materials for the preparation of desalination membranes and as modifiers for polyurethane foams.

\section{Experimental}

\subsection{Materials}

Phthalic acid, dibutyltin dilaurate (10 wt. (\%) in hexanes) and glycerol were obtained from Vetec, Sigma-Aldrich and Synth, respectively.

\subsection{Polyester synthesis}

Glycerol and Phthalic acid were mixed at $120^{\circ} \mathrm{C}$ under constant stirring. After the dissolution of the acid in glycerol, the dibutyltin 
dilaurate catalyst $(0.15$ wt. $(\%))$ was added and the temperature was increased up to $160{ }^{\circ} \mathrm{C}$ and was kept at this temperature for 1 hour. The materials were dried under vacuum at $50{ }^{\circ} \mathrm{C}$ giving rise to the POLF series. The materials were obtained as powders, as shown in Figure 1. The formulation used for the POLF syntheses are summarized in Table 1.

\subsection{Characterization methods}

\subsubsection{Infrared spectroscopy (FTIR)}

The infra-red spectra were recorded on a Spectrum One (Perkin Elmer) in the range between $4000-500 \mathrm{~cm}^{-1}$. The samples were analyzed as films.

\subsection{2. $\mathrm{X}$ ray powder diffraction $(\mathrm{XRD})$}

The $\mathrm{X}$ ray patterns were collected on a Shimadzu XRD-600 diffractometer, with $\mathrm{Cu}-\mathrm{K} \alpha$ radiation $(\lambda=1.54 \AA), 30 \mathrm{kV}$ potential and $20 \mathrm{~mA}$ current. The samples were analysed as powders.

\subsubsection{Thermogravimetric Analysis (TGA)}

The thermal stability of the polyesters was evaluated by a thermobalance TGSDTA 851 (Metler Toledo). The samples were heated from $25^{\circ} \mathrm{C}$ up to $1000{ }^{\circ} \mathrm{C}$ under $\mathrm{N}_{2}$ at heating rate of $20^{\circ} \mathrm{C} / \mathrm{min}$.

\subsubsection{Differential scanning calorimetry (DSC)}

The thermal behaviour was analyzed on a DSC 60 (Shimadzu) calorimeter, at temperatures between 25 and $600{ }^{\circ} \mathrm{C}$. The heating rate was $20^{\circ} \mathrm{C} / \mathrm{min}$.

\subsubsection{Scanning electron microsocopy (SEM)}

The morphological analysis was carried out using a SS 550 Scanning Electron Microscope (Shimadzu). The acceleration voltage was $7 \mathrm{kV}$ and the samples were sputtered with gold prior to the analysis. The samples were analyzed as powders.

\section{Results}

\subsection{Polycondensation process}

The polyesters were produced through a polycondensation reaction between glycerol and phthalic acid. The molecular structure

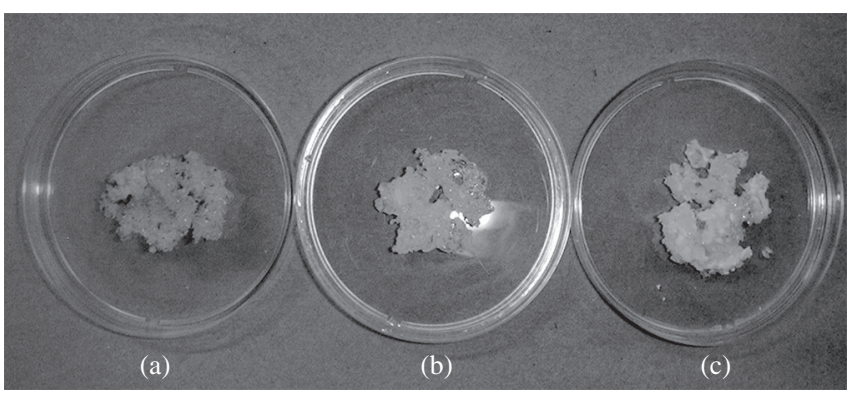

Figure 1. a) POLF I; b) POLF II; and c) POLF III.

Table 1. Molar ratio from POLF series.

\begin{tabular}{cc}
\hline Samples & Molar ratio (glycerol/phtalic acid) \\
\hline POLF I & $1: 1$ \\
POLF II & $1: 1.5$ \\
POLF III & $1: 2$ \\
\hline
\end{tabular}

of the polyesters is strongly influenced by the molar ratio between the monomers. An equimolar mixture of glycerol and phthalic acid should produce polyester with alcohols group, even if the esterification proceeds in quantitative yield. Therefore, the polyester POLF I should contain more un-reacted alcohol groups, than the POLFII and POLFIII. Conversely, the POLFIII should contain more un-reacted carboxylic acid groups, on account of the excess of phthalic acid, used for the preparation of POLFIII polymer.

The generic polymerisation reaction is depicted bellow.

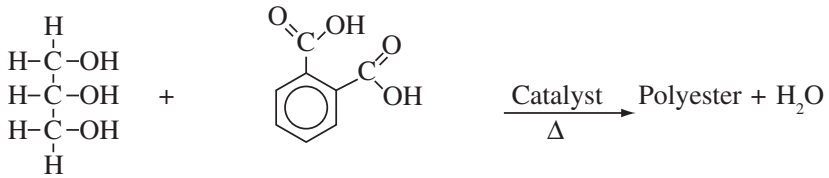

\subsection{Materials characterization}

\subsubsection{Infrared spectroscopy (FTIR) ${ }^{20}$}

Infrared spectroscopy was used for the characterisation of the molecular structure of the POLF polymers. The infrared spectra are shown in Figure 2. The absorption due to the $-\mathrm{CH}_{2}$ - and $-\mathrm{CH}$ groups of the esterified and un-reacted glycerol are seen in a envelop at 2950, 2932 and $2855 \mathrm{~cm}^{-1}$, which are associated to the stretching of the C-H of aliphatic compounds. The $\mathrm{C}-\mathrm{H}$ stretching of the phenylene ring of the phthalic acid can be identified by the absorption at $3070-3040 \mathrm{~cm}^{-1}$. The absence of absorption at $1711 \mathrm{~cm}^{-1}$ (assigned to - $\mathrm{COOH}$ dimmers) evidenced that the esterification reaction was almost complete for all the polyester, therefore the absorption between $3300-3000 \mathrm{~cm}^{-1}$ is associated to adsorbed water and un-reacted -OH groups (POLF I and POLF II) from glycerol (Table 2).

Table 2. Most important absorption and corresponding assignments.

\begin{tabular}{ll}
\hline Wave number $\left(\mathrm{cm}^{-1}\right)$ & \multicolumn{1}{c}{ Assignment, moeity } \\
\hline $3.070-3040$ & stretching $(\mathrm{C}-\mathrm{H})_{\text {aromatic }}$, phthalic acid- \\
$3300-3000$ & stretching $(\mathrm{O}-\mathrm{H})$, phthalic acid and glycerol \\
$2950-2932-2855$ & stretching $(\mathrm{C}-\mathrm{H})_{\text {aliphatic }}$, glycerol \\
$1735-1765$ & stretching $(\mathrm{C}=\mathrm{O})_{\text {ester }}$ esterified phthalic acid \\
1594 & stretching $(\mathrm{C}=\mathrm{C})_{\text {aromatic }}$, phthalic acid \\
1215 & bending $\mathrm{C}-\mathrm{C}(=\mathrm{O})-\mathrm{O}$, esterified phthalic acid \\
\hline
\end{tabular}

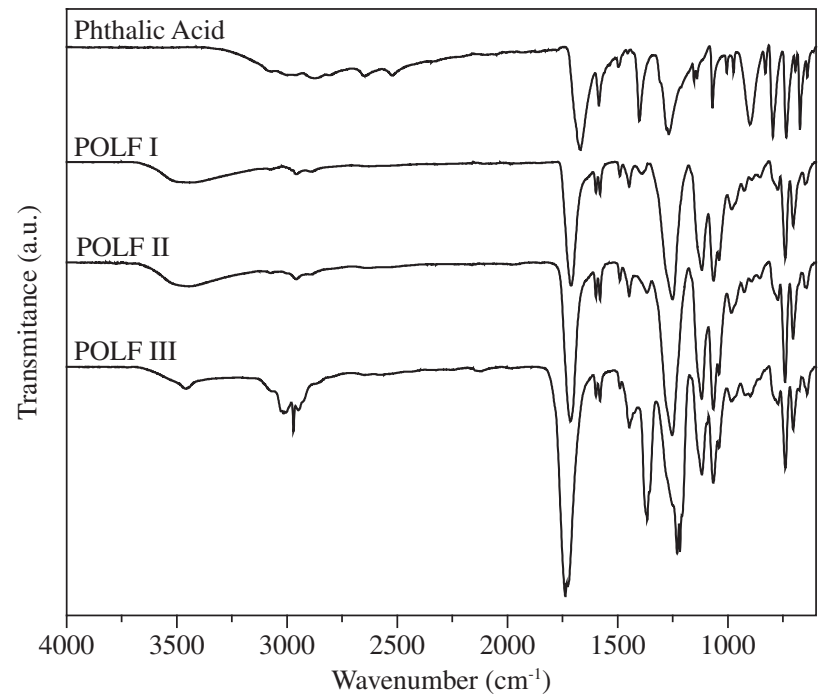

Figure 2. Fourier-transform infrared spectra from POLF series. 


\subsubsection{Differential scanning calorimetry (DSC)}

The DSC curves exhibited endothermic peaks centred at 373 , 373 and $364{ }^{\circ} \mathrm{C}$ for the polymers POLF I, II and III respectively (Figure 3). These peaks can be assigned to the degradation of the polymer chains.

\subsubsection{Thermogravimetric analysis (TGA)}

Figure 4 contains the TGA curves for the polymers investigated in the present work. The thermal stability, which was evaluated by the temperature associated to $10 \%$ weight loss, was POLFI $<$ POLFII $<$ POLF III. This first step is related to the elimination of residual (or adsorbed) water molecules. The decomposition of the polymer backbone took place at temperatures higher than $305^{\circ} \mathrm{C}$, and corresponded to the most important and fastest decomposition pathway of the POLF polymers. The amount of residue after the complete pyrolysis of the sample was $1-2 \%$. The POLF polymers are less stable than other polyesters obtained from aromatic carboxylic acids (terephthalic esters, naphthalenedicarboxylic esters), which are stable at temperatures up to $426^{\circ} \mathrm{C}^{21-23}$

The main degradation mechanism of polyesters having high molecular weight is the formation of alkenes, through $\beta$-elimina$\operatorname{tion}^{24-27}$, the trans-esterification and the rearrangements involving the end-groups play also a decisive role on the thermal stability of

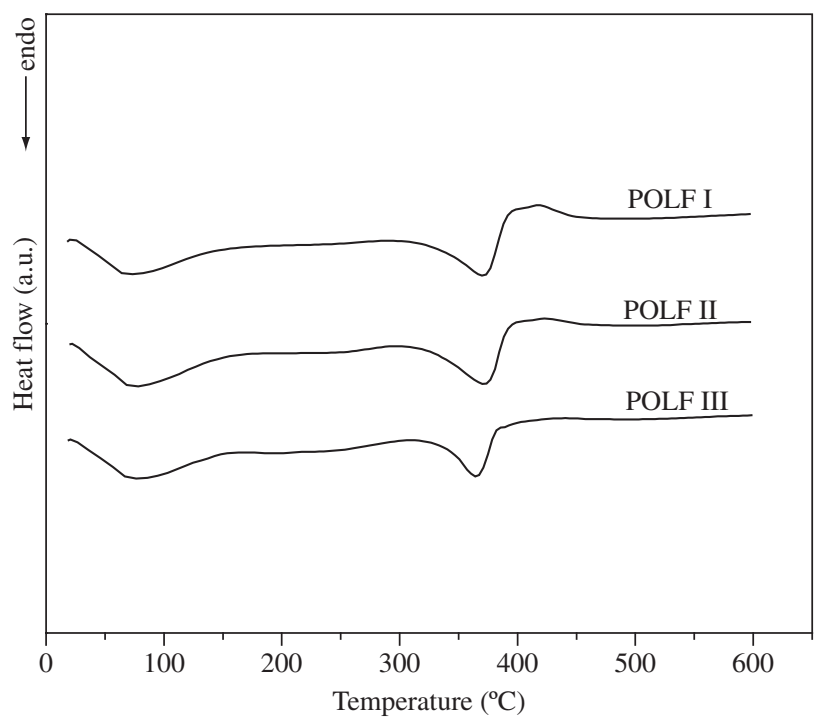

Figure 3. Differential scanning calorimetry curves from POLF series.

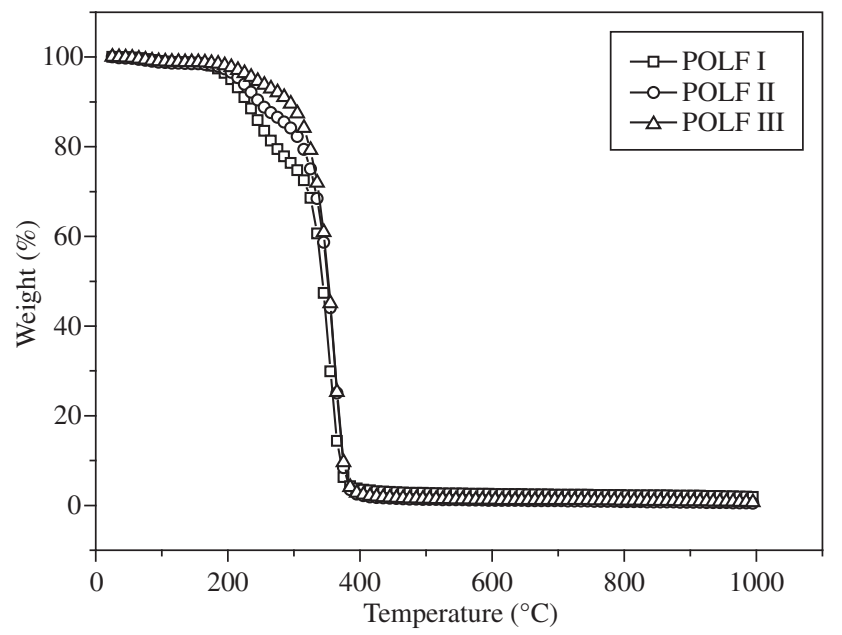

Figure 4. Thermogravimetric analysis curves from POLF series. polyesters ${ }^{28}$. It seems to be the case here, since the degradation of the POLF polymer may be accelerated by depolymerisation reactions involving residual alcohol and carboxylic groups.

\subsubsection{X ray powder diffraction (XRD)}

The XRD patterns of the polymers POLF I and POLF II had a diffuse halo at $2 \theta=20$, which is associated to the intra-chain segment distance of $0.45 \mathrm{~nm}$ (Figure 5). More defined peaks can be identified in the diffratogram of POLF III. Although the DSC curves gave no evidences for crystallinity for the POLF polymers, the XRD pattern of POLF III suggest that the presence of rigid aromatic rings, stemmed from the phthalic acid, lead to more rigid structures, which should be more prone to crystallize than fully aliphatic polyesters. In fact the molar proportion between phthalic acid and glycerol used for the synthesis of POLF III contributed to the formation of ramified polymers having $-\mathrm{COOH}$ pedant groups, since there is an excess of $-\mathrm{COOH}$ (carboxylic acid groups) group in relation to - $\mathrm{OH}$ (alcohol groups). Furthermore, a higher amount of phthalic acid should preclude the molecular motions, due to the rigidity of the aromatic rings, and should facilitate the packing of the polymer chains in crystalline lattices.

\subsubsection{Scanning electron microsocopy (SEM)}

The SEM micrographs of the POLF powder (Figure 6) had a very smooth surface, even though the materials had been analyzed as

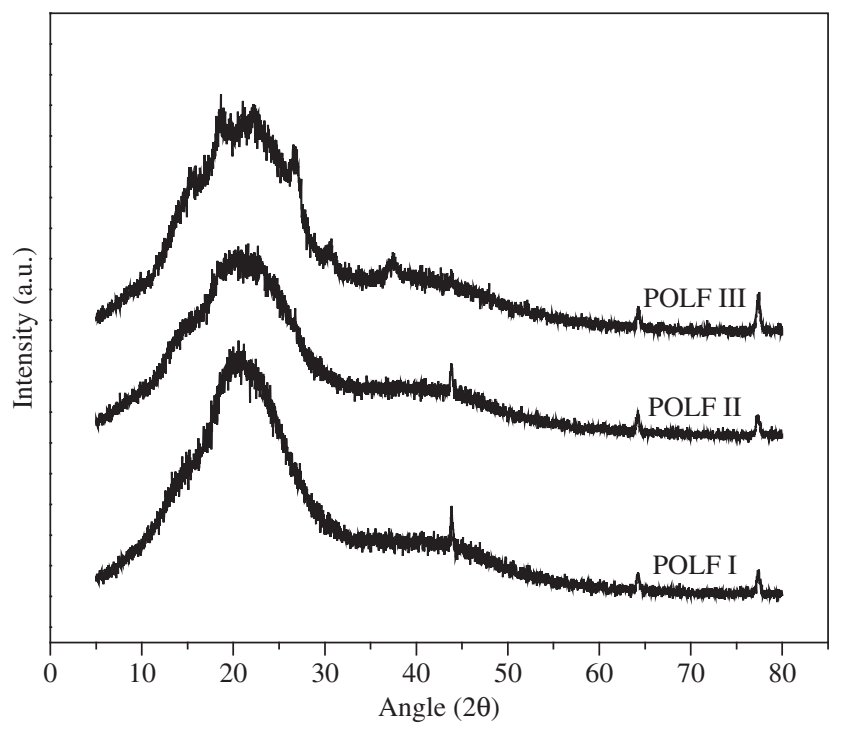

Figure 5. $\mathrm{X}$ ray powder diffraction from POLF series.

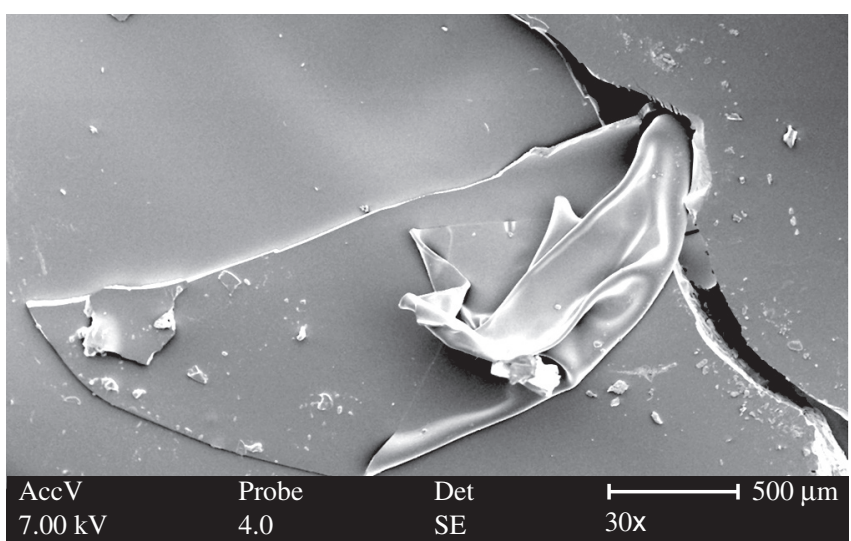

Figure 6. Scanning electron microsocopy from POLF II sample. 
powder. No evidences for phase separation could be found; therefore the POLF polymers are homogeneous.

\section{Conclusions}

The polycondensation between phthalic acid and glycerol produced new polyester with good thermal stability at temperatures lower than $200{ }^{\circ} \mathrm{C}$. XRD results evidenced that an incipient crystallinity of the materials could be attained for the polyester containing higher amounts of phthalic acid.

\section{Acknolwdegments}

The authors acknowledge FAPESB (Fundação de Amparo à Pesquisa do Estado da Bahia) for the financial and technical support given to this work.

\section{References}

1. http://www.biodieselbr.com/biodiesel/glicerina/biodiesel-glicerina.htm (accessed on 10/10/05)

2. DeLucca NW, Elabd YA. Polymer Electrolyte Membranes for the Direct Methanol Fuel Cell: A Review. Journal of Polymer Science Part B Polymer Physics Edition. 2006; 44(16):2201-2225.

3. Demarconnay L, Brimaud S, Coutanceau C, Leger, JM. Ethylene glycol electrooxidation in alkaline medium at multi-metallic Pt based catalysts. Journal of Electroanalytical Chemistry. 2007; 601(1-2):169-180.

4. Li, L, Xing, YC. Pt-Ru nanoparticles supported on carbon nanotubes as methanol fuel cell catalysts. Journal of Physical Chemistry C. 2007; 111(6):2803-2808.

5. Ospinai, M, Rosario, GE, Chaparro, K, Diaz, Y, Santiago, L, Lorenzo, I, Colluci, J. Anais do 2005 Annual Meeting AICHE; 2005 Oct. 10; Cincinatti, Ohio, USA.

6. http://www.fuelcellsworks.com/Supppage4762.html (accessed on 08/11/2006).

7. http://www.engr.wisc.edu/news/headlines/2003/Mar10.html (accessed on 08/11/2006).

8. Stumbe JF, Brunchmann B. Hyperbranched polyesters based on adipic acid and glycerol. Macromolecular Rapid Communications. 2004; 25(9):921-924.

9. Bucio E, Lara-Estevez JCI, Ruiz-Trevino FA, Acosta-Huerta, A. Synthesis and characterization of new polyesters derived from diphenols and aromatic diacids chlorides. Polymer Bulletin, 2006, 56(2-3):163-170.

10. Serad GE, Freeman BD, Stewart ME, Hill AJ. Gas and vapor sorption and diffusion in poly(ethylene terephthalate). Polymer. 1993; 34(19):4060-4067.

11. http://www.degussa-hpp.com/eng/products/hpp/vestodur.shtml (accessed on $08 / 11 / 2006$ ).

12. http://www2.basf.de/basf2/html/plastics/englisch/pages/konstr/ultradu. htm\#sub02 (accessed on 08/11/2006).
13. Grande JA. Design innovation drives PC/PBT bumper comeback. Modern Plastics. 1997; 74(8):32.

14. Saur K, Fava JA, Spatari S. Life cycle engineering case study: Automobile fender designs. Enviromental Progress. 2000; 19(2):72-83.

15. Antic VV, Vuckovic MV, Djonlagic J. Application of reactive siloxane prepolymers for the synthesis of thermoplastic poly(ester-siloxane)s and poly(ester-ether-siloxane)s. Journal of Serbian Chemical Society. 2007; 72(2):139-150.

16. Vuckovic MV, Antic VV, Dojcinovic BP, Govedarica MN, Djonlagic J. Synthesis and characterization of poly(ester ether siloxane)s. Polymer International. 2006; 55(11):1304-1314.

17. Ezquerra, TA. In: Fakirov, S. editor. Handbook of Condensation Thermoplastic Elastomers. Willey-VCH, Weinheim Chapter 8; 2005. p. 227-237.

18. Metz SJ, Van der Ven WJC, Potreck J, Mulder MHV, Wessling M. Transport of water vapor and inert gas mixtures through highly selective and highly permeable polymer membranes. Journal of Membrane Science. 2005; 251(1):29-41.

19. Roslaniec, Z. In: Baltá Calleja, FJ and Roslaniec, Z, editors. Block Copolymers. Marcel Dekker, Basel Chapter 17; 2000. p. 451-478.

20. Silverstein M, Bassler G, Marril C. Identificação Espectrométrica de Compostos Orgânicos. 5. ed. Guanabara: Koogan; 1994.

21. Kelsey, DR, Kiibler, KS, Tutunjian, PN. Thermal stability of poly(trimethylene terephthalate). Polymer. 1999; 46(21):8937-8946.

22. Sun, YM, Wang, CS. Preparation and characterization of poly(ethylene1,4-cyclohexanedimethylene arylate). European Polymer Journal. 1999; 35(6):1087-1096.

23. Sun, YM, Shieh, JY, Wang, CS. Novel copolyesters containing naphthalene structures. 3. Poly(alkylene naphthalate terephthalate). European Polymer Journal. 1997; 33(3):317-323.

24. Zorba T, Chrissafis K, Paraskevopoulos KM, Bikiaris, DN. Synthesis, characterization and thermal degradation mechanism of three poly(alkylene adipate)s: Comparative study. Polymer Degradation and Stability. 2007; 92(2):222-230

25. Chrissafis K, Paraskevopoulos KM, Bikiaris, DN. Effect of molecular weight on thermal degradation mechanism of the biodegradable polyester poly(ethylene succinate). Thermochimica Acta. 2006; 440(2):166-175.

26. Aoyagi Y, Yamashita K, Doi Y. Thermal degradation of poly[(R)-3hydroxybutyrate], poly[epsilon-caprolactone], and poly[(S)-lactide]. Polymer Degradation and Stability. 2002; 76(1):53-90.

27. Arvanitoyannis I, Nakayama A, Kawasaki N, Yamamoto N. Novel starshaped Polylactide with glycerol using stannous octoate or tetraphenyl tin as catalyst.1. synthesis, characterization and study of their biodegradability. Polymer. 1995; 36(15):2947-2956.

28. Van Bennekom ACM, Willemsen PAAT, Gaymans RJ. Amide-modified poly(butylene terephthalate): Thermal stability. Polymer. 1996; 37(24):5447-5459. 